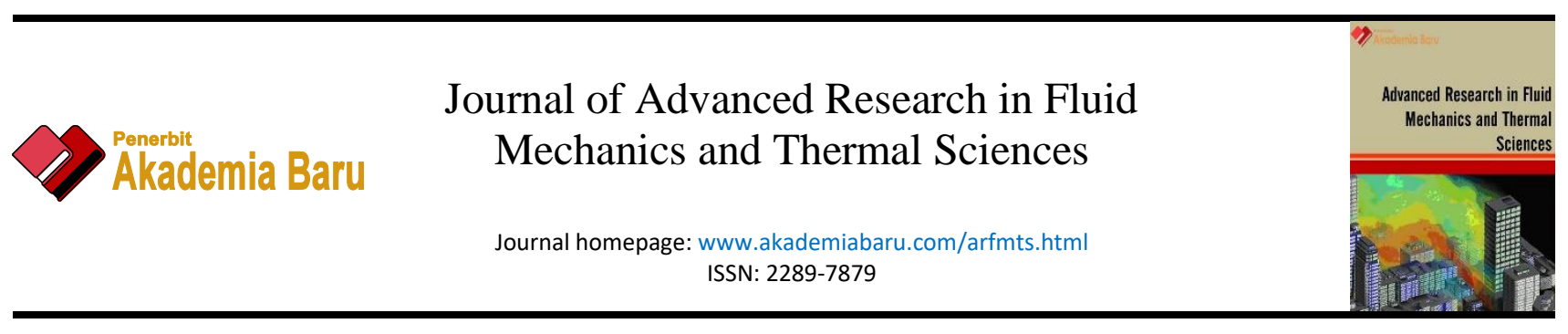

\title{
Shape Design Thermal Improvement of the Exhaust Manifold
}

\author{
Wisam Nasser Assi ${ }^{1,}$, Assim S. Alaawe ${ }^{1}$, Mohammed Ali Nasser Ali $^{1}$ \\ Middle Technical University, Technical Engineering College-Baghdad, Iraq
}

ARTICLE INFO ABSTRACT

\section{Article history:}

Received 26 November 2019

Received in revised form 6 January 2020

Accepted 11 January 2020

Available online 18 April 2020

\section{Keywords:}

Exhaust manifold; design improvement; numerical analysis; experimental testing; thermal distribution; thermal loading

\begin{abstract}
The exhaust manifold is the bridge connecting the cylinder head to the catalytic converter, which collects the exhaust gases from the multiple cylinders and sends them to one pipe exhaust. The temperature of the exhaust gases in the manifold reaches so high as $800^{\circ} \mathrm{C}$. So, the exhaust manifold is affected by thermal loading due to the high-temperature gradient. This paper presents a numerical and experimental analysis implemented a typical cast iron exhaust manifold. In this study, the temperature extracted from the manifold done by employing different shape types of longitudinal fin mounted on the external surface of the manifold. In the numerical analysis, the model generated by Solidworks software firstly and simulated using ANSYS Workbench R19 for different cases. The experimental work adopted two best numerical modelling results, which have been selected for fabrication and testing experimentally. Results found that the effect of fin installation gives a better reduction in the surface temperature along the exhaust manifold, especially in the high thermal loaded middle section, where the temperature drops to more than 100 ${ }^{\circ} \mathrm{C}$. Also, the Sinusoidal fin model achieved slightly better results than the straight model despite the small surface area. Moreover, the comparison between the numerical and experimental works gives a good matching reached $1.8 \%$, which is assisting the numerical analysis.
\end{abstract}

Copyright $@ 2020$ PENERBIT AKADEMIA BARU - All rights reserved

\section{Introduction}

A prerequisite in the design of the exhaust manifold that subjects to high temperature are the durability. In the modern spark-ignition engines that are characterized downsized and high efficiency, the exhaust manifold exposed gases at temperature up to $800{ }^{\circ} \mathrm{C}$.To maintain durability the metal temperature of manifold must be lower than transformation temperature (proximate $750{ }^{\circ} \mathrm{C}$ for cast iron) [1]. In addition, it allows much reduced pre-turbine gas temperature which means cheaper turbo materials could be used, thus reducing engine unit cost [2]. A few applications require low

\footnotetext{
* Corresponding author.

E-mail address: wisamnaserassi@gmail.com (Wisam Nasser Assi)
} 
manifold skin temperatures. For instance, the Mining Safety also, Health Agency (MSHA), the Airs Exposable (ATEX) mandate and marine social orders require that manifold skin temperatures stay underneath $200^{\circ} \mathrm{C}$ for certain mines. One approach to achieve this goal is to implement liquid cooling for the exhaust manifold [3]. However, the use of an extensive water-cooling system requires a separate water circuit, controls, and a radiator capable of rejecting heat. The pump used is to drive the coolant through the system is one source of lost energy brake addition, the exhaust manifold cooling circuit takes space from the engine room. Cartwright et al., [3] used an external cooling circuit to determine heat rejection and skin temperature experimentally. Ethylene-glycol-based antifreeze use as coolant passed through manifold water- jacket to reduce surface temperatures. Increasing brake power causes increase temperature and mass flow rate of exhaust gas which means a large amount of heat rejection. Jha et al., [4] installed a water injection system inside the intake manifold for a single-cylinder gasoline engine to reduce the temperature of the exhaust gases. The experimental study was conducted by changing the volumetric flow rate of the injected water twenty - one time. The author concluded a decrease in the temperature of the gas by increasing the amount of water injected. Milanovic et al., [5]. Studied performance of liquid-cooled exhaust manifold used in the marine by commercial computational fluid dynamic (CFD) software. Compared to Experimental data with the CFD results was present. Investigate effect many parameters as (coolant flow rate, engine rotational speed, exhaust gas inlet temperature, and coolant inlet temperature) on the efficient of the exhaust manifold. Saravanan et al., [6] Studied of reducing surface temperature and improving the mechanical properties of the cast iron exhaust manifold by coating the inner and outer surface using some materials to improve performance and reduce emissions. Hoseini et al., [7] Studied the heat distribution in another part of the exhaust system (EGR cooler). U-shaped wavy tubes used to cool exhaust gas in two directions parallel and perpendicular. The author concluded that the heat transfer coefficient enhances of $25 \%$ with a perpendicular direction. The effect of longitudinal fins on improving the characteristics of the heat transfer coefficient of a finned channel was studied numerically by Al Doori [8]. The results showed significant enhancement for Nusselt number with increase fins number.

To data surprisingly, reduce the thermal load on the exhaust manifold using longitudinal fins has not been closely investigated. This research attempt to find improvements for the shape design of exhaust manifold made of cast iron aims to reduce the thermal load and thermal stresses which are the main cause of design failure. In the present study, longitudinal fins were installed on the external exhaust manifold wall to increase the surface area of heat transfer. This technique considered inexpensive and does not require the addition of accessory devices that consume part of the engine's power and take space from the engine room.

\section{Numerical Analysis}

The numerical analysis consists of preprocessing, solving and post-processing. The preprocessing deals with the exhaust manifold and the added fins types geometrical modeling. Moreover, the boundary conditions which depend on the materials selected, testing operating conditions, types of heat transfer included in the simulation as convection and conduction with the flow specification and the meshing of the models. These boundary conditions will be described in detailed. A SOLIDWORKS software was used to generate the geometrical model of the exhaust manifold and the added fins types. The dimensions of an exhaust manifold of the engine are recorded based on the reverse engineering. Then, employing SOLIDWORKS software to create the 3D model. The exhaust manifold of the engine consists of four $37 \mathrm{~mm}$ diameter, the first cylinder exhaust ports and the fourth were linked together, and the other two equally, then the two linked couple above are connected together 
at the end of the exhaust. This form is termed 4-2-1exhaust manifold, as shown in Figure 1 . The fins type modeling produced as nine geometrical models of an exhaust manifold assemble with fins, which are; plain exhaust manifold (without adding fins) and eight finned exhaust manifold with various fin models differed in spacing, profile, thickness, and height. These assemble models were numerically simulated under different conditions of the engine operation, taking into account the design dimensions of the fins should match the size of the space available within the engine room and relative to the experimental testing rig. The engine room is filled with engine accessories and there is relatively little spacing available, according to the practical type of automotive engine used in the experimental work (Mercedes 1993), so there is a restriction in terms of dimensions to the limited distance. The fins dimension was $300 \mathrm{~mm}$ length along the exhaust manifold, while the height was limited to $50 \mathrm{~mm}$. The dimensions of the designed fins in all modeling cases are described in Table 1. Figure 2 and Figure 3 show the models and dimensions of these models.

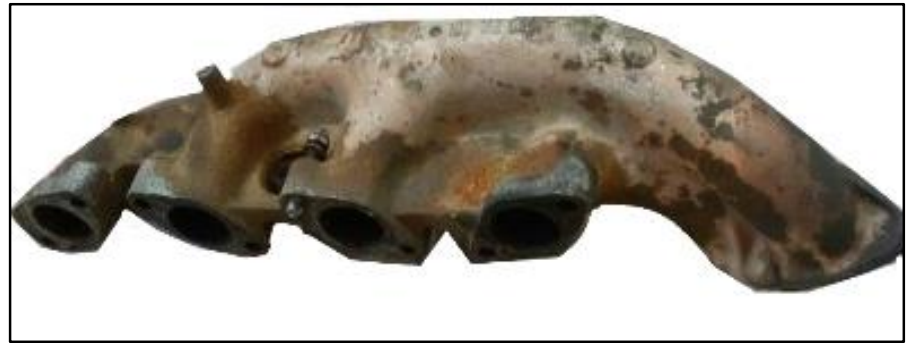

(a)

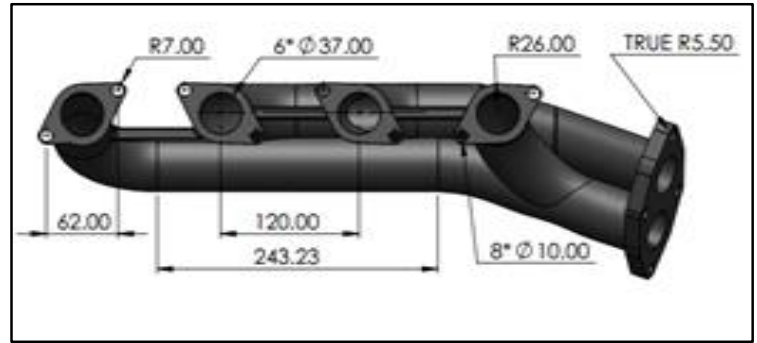

(b)

Fig. 1. 4-2-1 exhaust manifold: (a) original model, (b) Solidworks model

Table 1

The fins dimensions for all cases

\begin{tabular}{lllllll}
\hline Model & Case & Fin length & Fin spacing & $\begin{array}{l}\text { Fin } \\
\text { height }\end{array}$ & $\begin{array}{l}\text { Fin thickness } \\
(\mathrm{mm})\end{array}$ & $\begin{array}{l}\text { Number of } \\
\text { fins }\end{array}$ \\
\hline Fined manifold & 1 & 300 & 10 & 40 & 2 & 10 \\
(Straight fin) & 2 & 300 & 6 & 35 & 2 & 8 \\
& 3 & 300 & 6 & 40 & 2 & 8 \\
& 4 & 300 & 6 & 40 & 1 & 8 \\
Fined manifold & 5 & 300 & 6 & 46 & 2 & 8 \\
(Sinusoidal fin) & 6 & 300 & 10 & 40 & 2 & 6 \\
& 7 & 300 & 10 & 46 & 2 & 6 \\
\hline
\end{tabular}

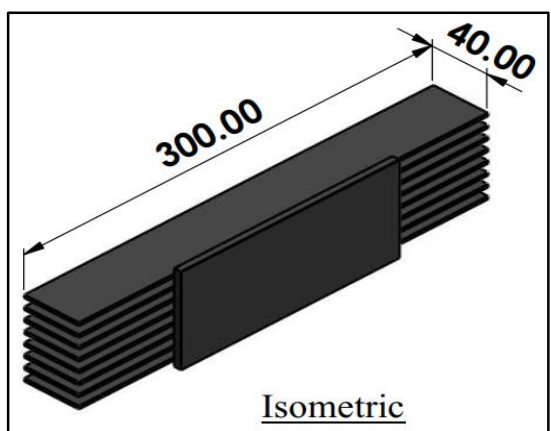

(a)

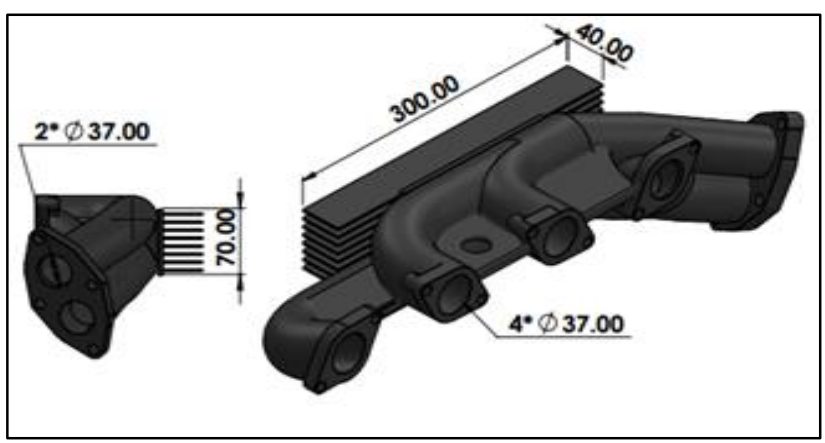

(b)

Fig. 2. (a) Straight fin assembly, (b) Fined exhaust manifold model 


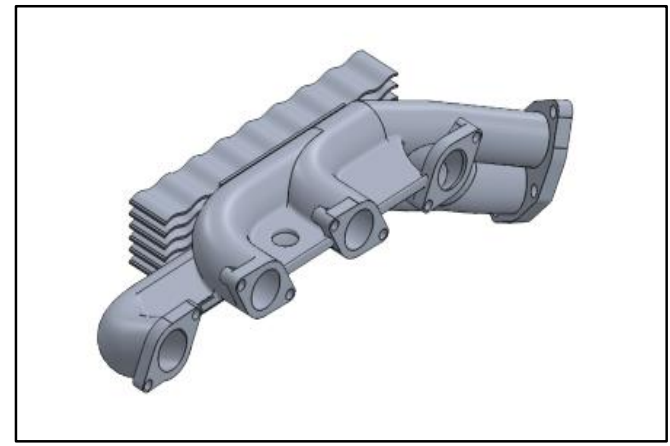

(a)

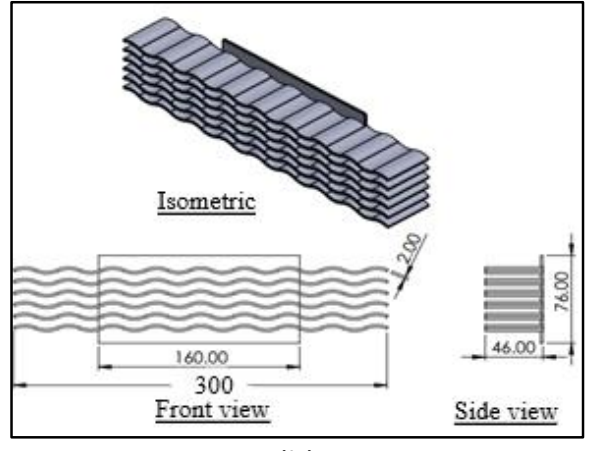

(b)

Fig. 3. (a) Sinusoidal fin assembly, (b) Finned exhaust manifold

\subsection{Boundary Conditions}

\subsubsection{Material selection}

One of the important boundary conditions in the numerical analysis is the material type of the solid parts (manifold and fins) and the flowing fluids. Two types of fluid have been used in the present simulation, Air for an external domain that represents air incoming from engine fan and the flue gas was selected as the working fluid inside the exhaust manifold. Flue gas is a mixture of combustion products of fuel and air. Table 2 produced the equations to calculate the properties of flue gas based on the temperature. The material selected for the exhaust manifold was gray cast iron, while the material of the added fins was aluminum alloy. The logic behind selecting aluminum alloy due to good dispersion, easy handling and forming, and good conductivity. The details of the properties of the material used in the present work are described in Table 3.

Table 2

Properties equations of exhaust gas [9]

\begin{tabular}{ll}
\hline Propriety & Equation \\
\hline Density $\rho\left(\mathrm{kg} / \mathrm{m}^{3}\right)$ & $\frac{353}{T_{g}}$ \\
Viscosity $(\mu)$ & $1.384 \times 10^{-5}+2.68 \times 10^{-8} T_{g}$ \\
Thermal conductivity K $(\mathrm{W} / \mathrm{K} . \mathrm{m})$ & $8.459 \times 10^{-3}+5.7 \times 10^{-5} T_{g}$ \\
Specific heat Cp & $962.097+0.1507 T_{g}$ \\
\hline $\boldsymbol{T}_{\boldsymbol{g}}$ : Exhaust gas temperature in kelvin &
\end{tabular}

Table 3

Material Properties [10]

\begin{tabular}{lllll}
\hline Material & Type & Properties & & \\
& & Density $\left(\mathrm{kg} / \mathrm{m}^{3)}\right.$ & Specific heat $(\mathrm{J} / \mathrm{kg} . \mathrm{K})$ & Thermal conductivity $(\mathrm{W} / \mathrm{m} . \mathrm{K})$ \\
\hline Solid & Gray Cast Iron & 7200 & 510 & 45 \\
& Aluminum alloy & 2719 & 871 & 200 \\
Fluid & Air & 1.06 & 1.007 & 0.02808 \\
\hline
\end{tabular}

\subsection{Operating Conditions}

Two types of heat transfer conditions produced in the simulation of the models, these are convection heat transfer occurred at the inner and outer surface of the exhaust manifold and also the fins, while conduction heat transfer occurred through the walls of the manifold body and the fins. The governing differential equations were set up to describe the problem in the domain, it is important to adjust the boundary conditions that specify the values of the mass flow rate and 
temperature similar to that considered in the experimental solution of the problem. ANSYS-FLUENT software was employed in the numerical simulation, where the boundary conditions must be specified at each surface defined in the mesh generation process. Specifically, the information about the mass flow rate and temperature should be specified at each surface as shown in Figure 4 . While the testing operating conditions for certain cases are described in Table 4.

Table 4

Testing operating conditions

\begin{tabular}{lll}
\hline Engine speed (RPM) & Load (N.m) & Fuel (g/sec) \\
\hline 1000 & 24 & 0.467 \\
1400 & 24 & 0.619 \\
1800 & 24 & 0.856 \\
2200 & 24 & 1.121 \\
2600 & 24 & 1.270 \\
3000 & 24 & 1.524 \\
\hline
\end{tabular}

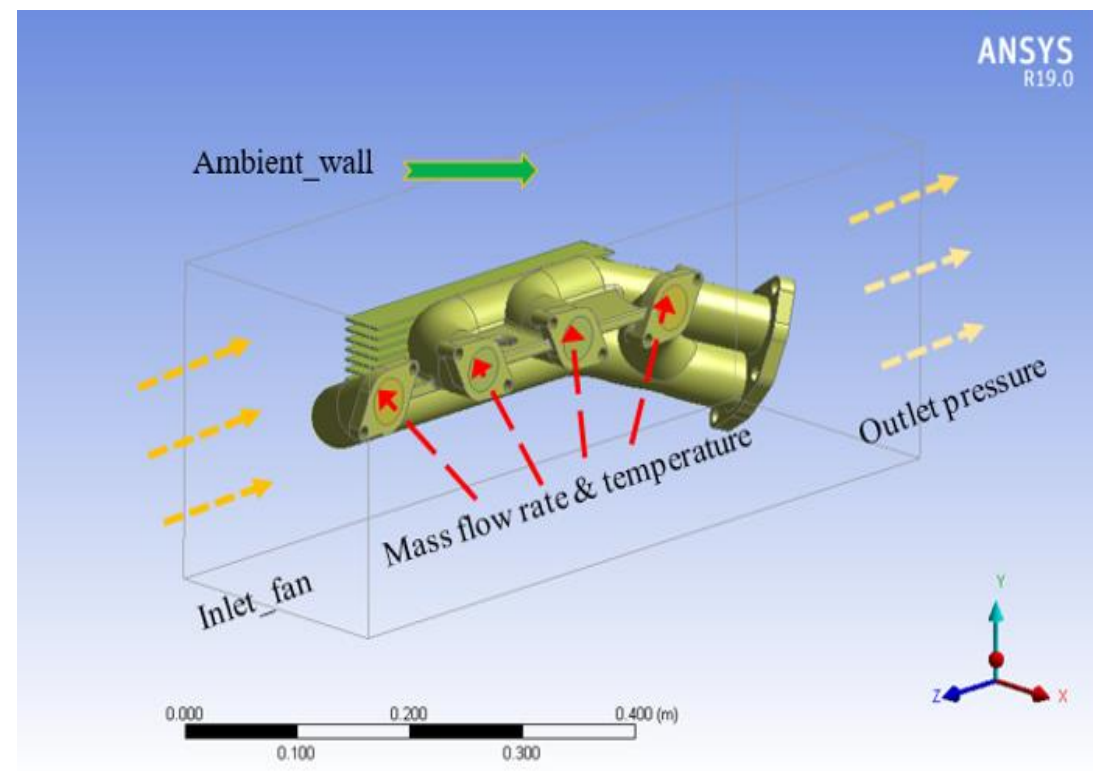

Fig. 4. The operating boundary conditions

\subsection{Grid Independent Test}

Before beginning to create the CFD generation runs, picking the correct mesh type influences the exactness of the solution and the speed of arriving results. The mesh independence study was done for the exhaust manifold. The aim behind this is to discover the best mesh properties for a precise solution. The procedure starts with a coarse mesh and normally refining it until the varieties saw in the results are littler than a foreordained satisfactory error. The adequate error is indicated by taking numerical precision and the time consuming into consideration. The number of elements varies from 3265891 to 6456754 of finned manifold meshing, it is needed a suitable approach for the assessment of mesh dependency and variation of the monitored parameters such as outlet gas temperature with a total element number as shown in Figure 5. 


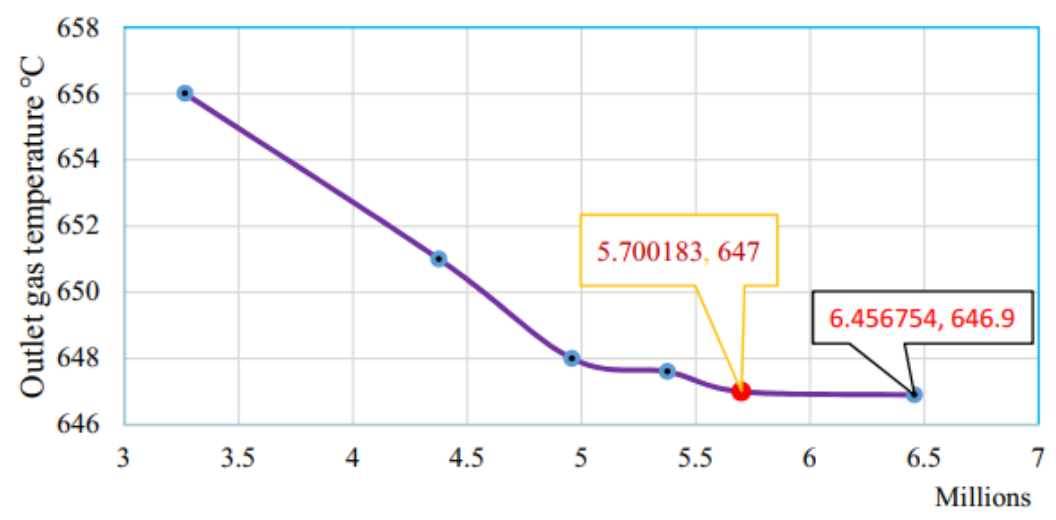

Number of elements

Fig. 5. The variation of exhaust gas temperature with a total element number

\subsection{Meshing Scheme}

There are mainly two types of approaches in volume meshing, structured and unstructured meshing. The structured mesh can be made of a hexahedral element, while the unstructured mesh can be made of tetrahedral, prism, pyramid elements. The complex geometry of the exhaust manifold and numerous domains (exhaust gas-solid - ambient) appropriate the employment of the assembly meshing. Assembly meshing indicated to meshing the whole model as a single mesh operation, contrasted with the part or body-based meshing, in which meshing happens in the part or body level respectively. They were two algorithms are accessible for assembly meshing; Cut Cell and Tetrahedrons. The cut cell manner (utilized in this investigation) is a Cartesian meshing, which is a general-purpose meshing approach conceived for ANSYS Fluent as shown in Figure 6 [11]. In the present work, the exhaust manifold used in the CFD analysis has been divided into 5700183 elements and 6145485 nodes.

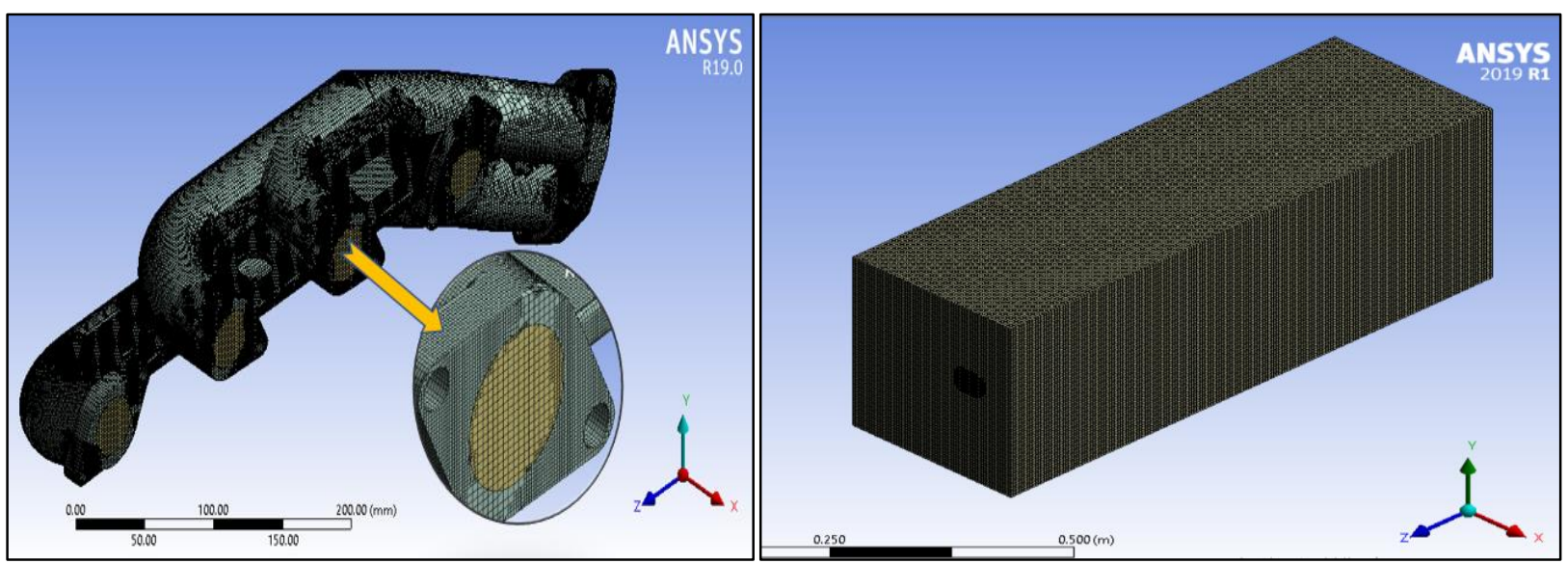

Fig. 6. Assembly meshing (cut cell method)

\subsection{Solving Process}

The CFD finite volume numerical method solution based on the ANSYS-FLUENT software to solve the governing equations of the flow field. The governing equations include the continuity (mass conservation), the Navier-Stokes equations of motion (momentum conservation) and energy equations in three dimensions for the fluid domain (flue gas). The set of the differential equations in 
a cylindrical form describing the transport of mass, momentum, and energy in a fluid [12], also the governing equation of the solid domain (manifold) [13]. Taken into consideration the assumptions that been settled in the software as follows.

\section{Assumptions}

i. The flow field is three-dimensional.

ii. The case is steady-state.

iii. The type of flow is turbulent.

iv. The physical properties of the air are assumed to be constant with temperature.

v. The physical properties of the gas are a function of gas temperature.

vi. The heat transfers by radiation and the internal heat generation are assumed negligible.

Three turbulent models the standard $(k-\omega)$ model, the SST $(k-\omega)$, and a realizable $(k-\varepsilon)$ model were used commonly in engineering applications to study the steady-state, three-dimensional turbulent flow because of these models available a good compromise between computational time and accuracy [14]. The chosen suitable turbulent model affects the accuracy of the numerical results. To further verify the best turbulent model for the present cases, four primarily turbulent models ( $k$ $\omega$, SST k- $\omega, \mathrm{k}-\varepsilon$ and $\mathrm{k}-\varepsilon$ RNG) were simulated using case (3000 rpm and 24 N.m load) with the same actual exhaust manifold dimensions, and the results were compared with the experimental testing data for the same operation conditions. The results showed that $k-\omega$ model was the most similar to the experimental testing data comparing with the other checked turbulent models with an estimated deviation ratio of $5.8 \%$ for the upper exhaust manifold pipe and $6.2 \%$ for the lower exhaust manifold pipe.

\section{Experimental Analysis}

To meet the experimental goals, a testing rig containing engine unit, dynamometer unit, and measuring instrumentations were used. The schematic drawing and photograph of the testing rig are shown in Figure 7. The spark ignition (SI) engine was equipped to operate with gasoline and Table 5, presents the main technical specifications of the testing engine.

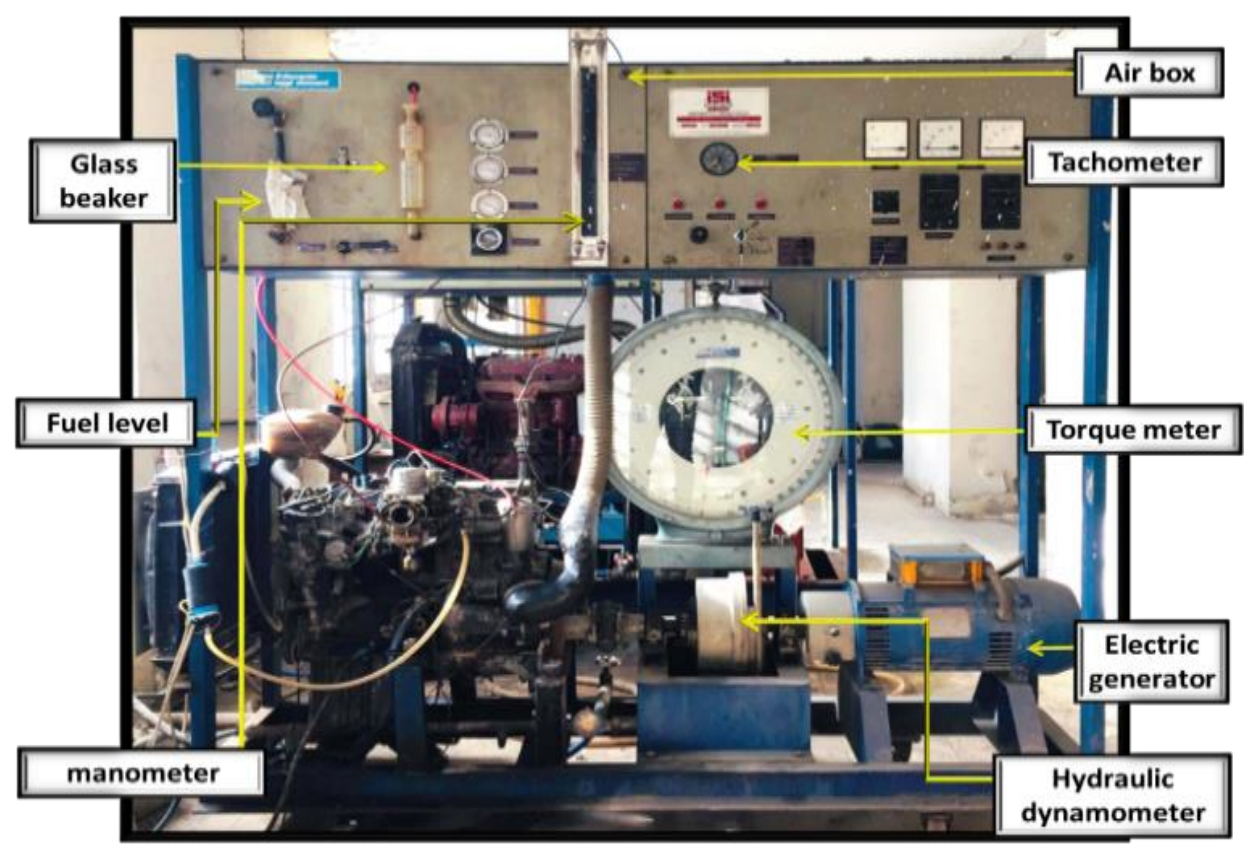

(a) 


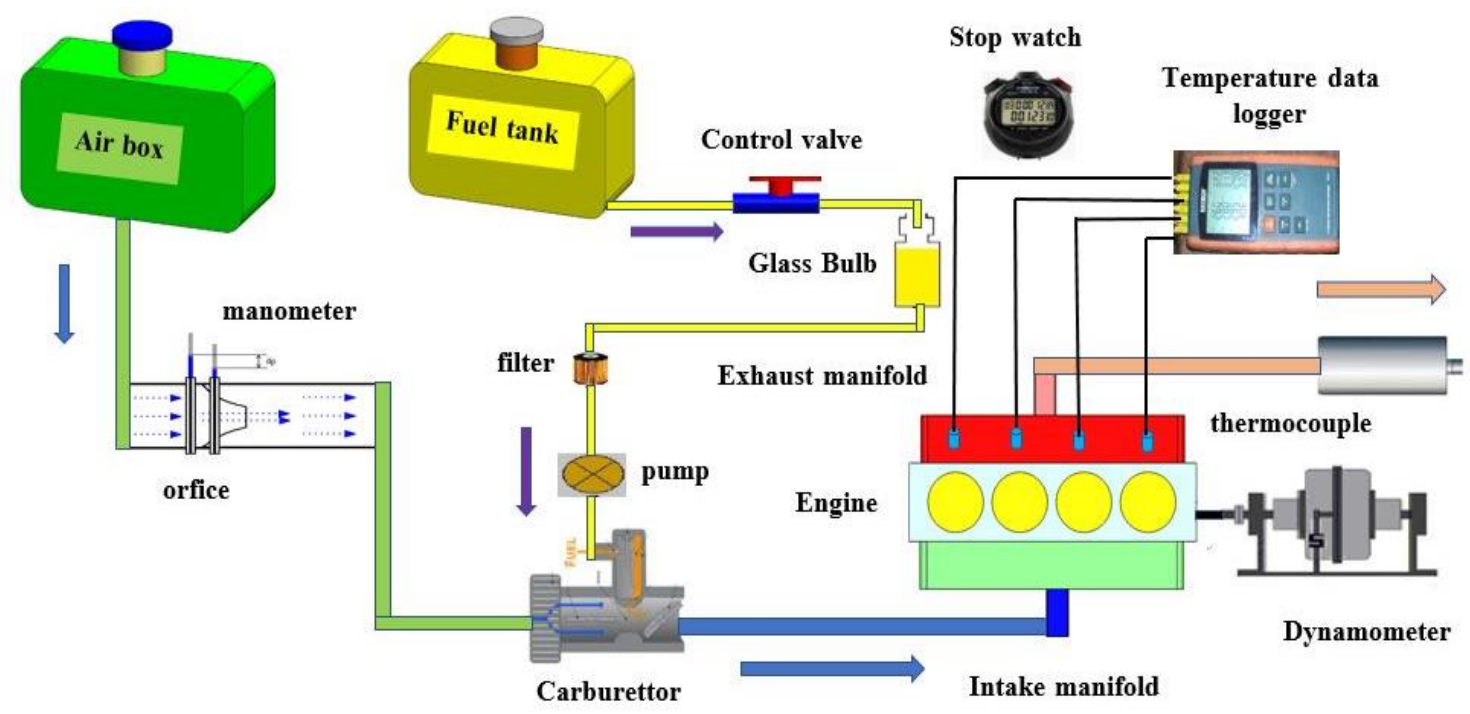

(b)

Fig. 7. Experimental testing rig, (a) schematic drawing (b) photograph

Table 5

Testing operating conditions

\begin{tabular}{|c|c|}
\hline Engine type & $\begin{array}{l}\text { Naturally aspirated } \\
\text { petrol }\end{array}$ \\
\hline $\begin{array}{l}\text { Engine } \\
\text { manufacturer }\end{array}$ & Mercedes-Benz \\
\hline Cylinders & Straight (Four-Stroke) \\
\hline $\begin{array}{l}\text { Displacement } \\
\text { volume }\end{array}$ & $1997 \mathrm{~cm}^{3}$ \\
\hline Bore $\mathrm{x}$ Stroke & $89 \times 80.25(\mathrm{~mm})$ \\
\hline $\begin{array}{l}\text { Connecting rod } \\
\text { length }\end{array}$ & $150(\mathrm{~mm})$ \\
\hline Compression ratio & $9: 1$ \\
\hline Max.power@ rpm & $\begin{array}{l}\text { 80kW (107.5 hp) @5500 } \\
\text { rpm }\end{array}$ \\
\hline Max. torque @ & 165 N·m (118 lb·) @ \\
\hline rpm & $3000 \mathrm{rpm}$ \\
\hline Fuel system & Carburetor \\
\hline Cooling & Water \\
\hline
\end{tabular}

The selection of the fins shape type depends on the best numerical results obtained. Then the manufacturing of the fins was done by a wire cut process for the straight fin which is consists of two parts. The first part was the fins base made of the rectangular plate $(7 \times 14) \mathrm{cm}$, containing $8 \mathrm{~cm}$ long parallel grooves with $2 \mathrm{~mm}$ width which are used to fix the fins and the second part was rectangular fins with $(4 \times 30 \times 0.2) \mathrm{cm}$, inserted vertically into the base as shown in Figure 8 . While the CNC cutting process was used to manufacture the sinusoidal fin by cutting an aluminum rectangular bar $(70 \times 65$ $\times 310) \mathrm{mm}$ with a cutting tool of $10 \mathrm{~mm}$ as shown in Figure 9 .

Exhaust gas-stream temperatures were estimated utilizing type $\mathrm{K}$ thermocouples with a 2-mm distance across wire uncovered intersection. These thermocouples were roughly situated at the gas stream centreline at the passageway to every one of the short exhaust manifold runners and at the manifold outlet. A sum of 6 stream temperatures was estimated over the exhaust manifold. External manifold system skin temperatures were estimated utilizing $1.5-\mathrm{mm}$ width type $-\mathrm{K}$ thermocouple wire with high-temperature protection. These thermocouples were settled on the manifold surface with thermal adhesive glue. Each skin thermocouple had a development alleviation and was tied set 
up utilizing treated steel strips over the protected wire. Outside skin temperatures were estimated in 9 zones over the manifold as shown in Figure 10. Notwithstanding part temperature estimations, type $-K$ uncovered wire thermocouples were utilized to quantify the fan stream air temperature radial neighboring the pivotal focal point of the manifold.

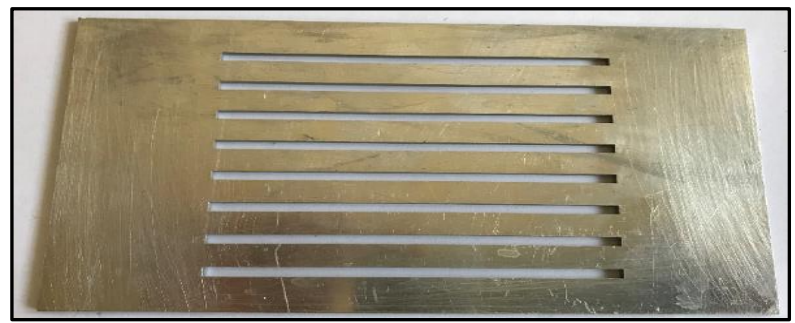

(a)

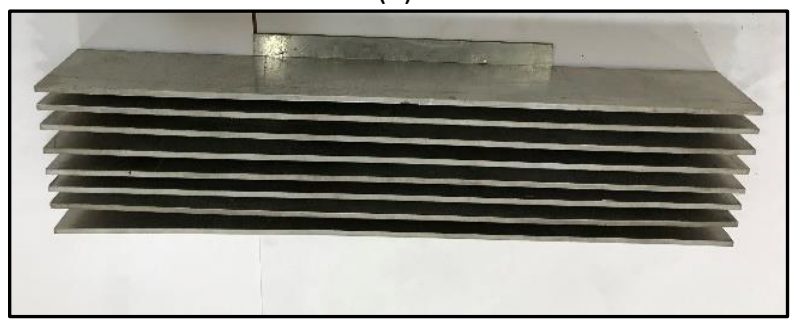

(c)

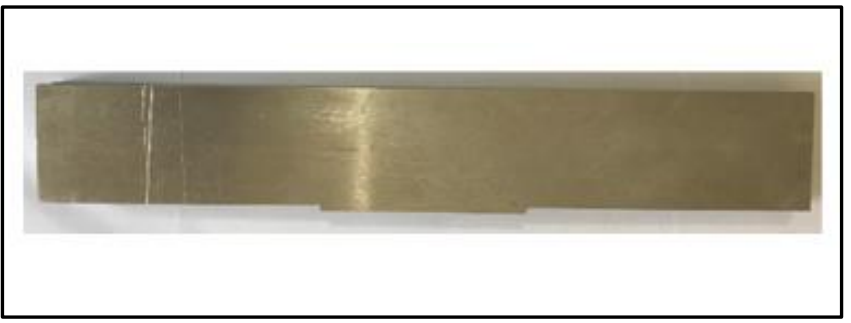

(b)

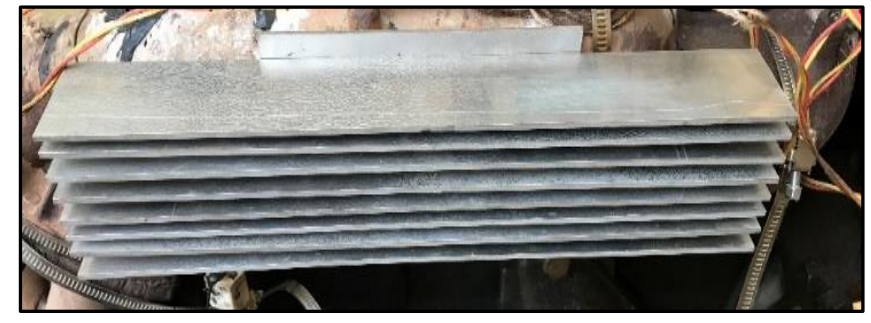

(d)

Fig. 8. Straight fin (a) fin base, (b) fins, (c) fins assemble, (d) fins on exhaust manifold

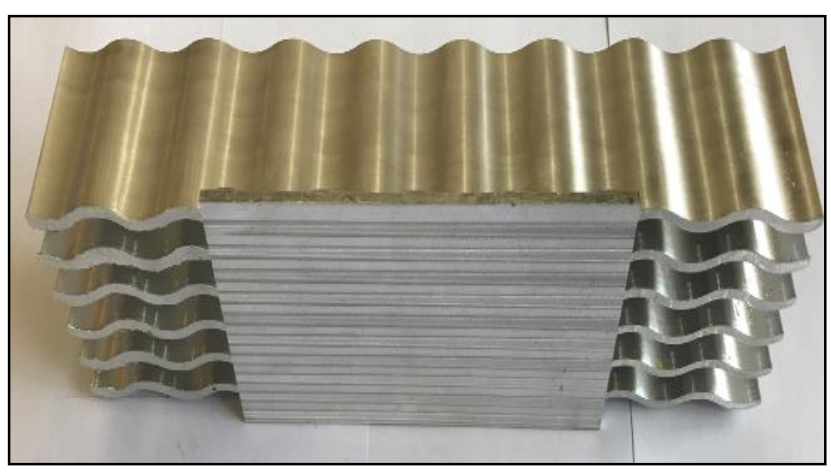

(a)

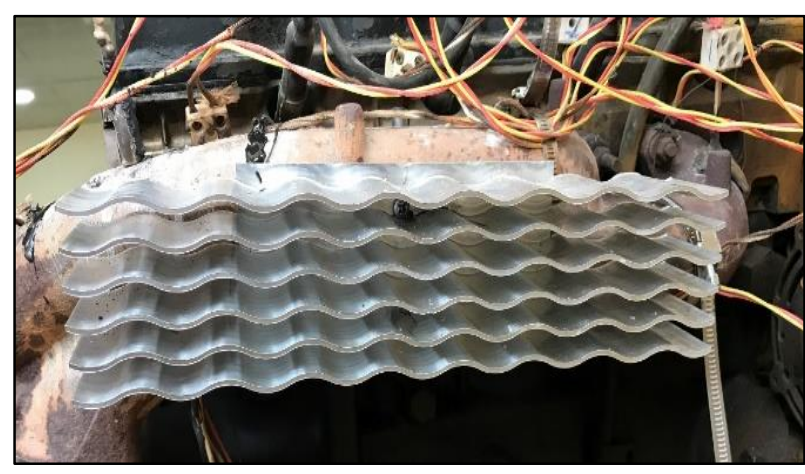

(b)

Fig. 9. Sinusoidal fin, (a) sinusoidal fin assembly (b) fins installed on the exhaust manifold

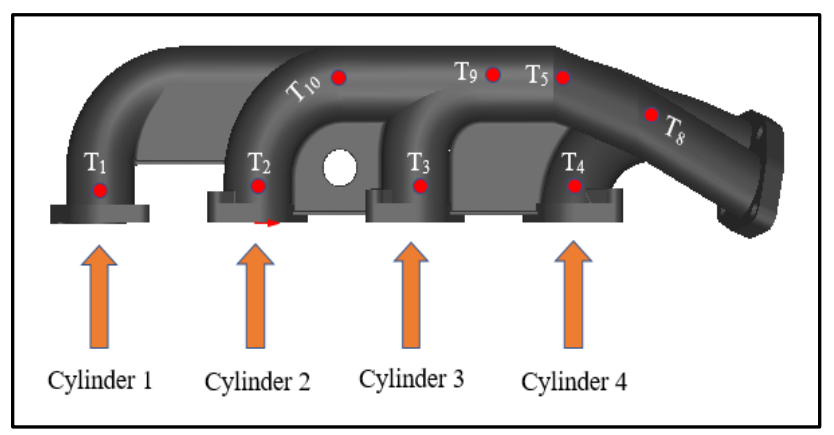

(a)

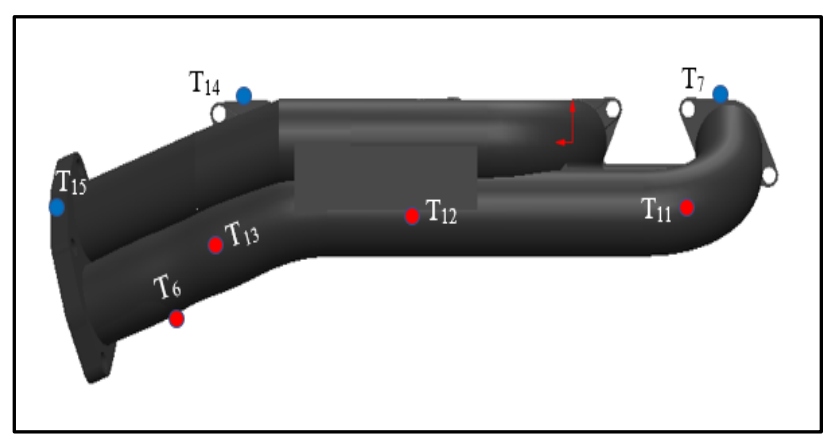

(b)

Fig. 10. Thermocouples locations on the exhaust manifold, (a) top view, (b) side view 


\section{Results and Discussions}

In this work, the concept of adding fins to the exterior body of the exhaust manifold to enhance the rate of heat transfer from the manifold through extracting the heat to the outside. Two geometrical models of fins type; straight and sinusoidal with several effective parameters were studied numerically and experimentally to find out the best performance achievements. The numerical simulation was carried out at the maximum experimental thermal loading, which represented by 3000 rpm engine speed and 67 N.m load.

\subsection{Numerical Results}

\subsubsection{Straight fin models}

The numerical modification analysis was used to simulate the effect of adding four kinds of fins individually to the exhaust manifold, where their specifications were mentioned in Table 1, also the geometrical shape as shown in Figure 2. The numerical results were studied at the same locations as the thermocouples located on the exterior surface of the manifold in the experimental work. The predicted mean manifold temperatures at different thermocouple locations and at the manifold-out exhaust gas temperature were presented in Table 6, described the distributions of skin temperature along the length of the upper and lower pipe of the manifold also shown in Figure 11. When 40-mm fins spaced $6 \mathrm{~mm}$ (case 3) apart were installed on the exhaust manifold, the lower pipe of the exhaust cooled about $100{ }^{\circ} \mathrm{C}$ at TC-12 compared to the exhaust without fins. The exhaust gas cooling was dispersed only $5{ }^{\circ} \mathrm{C}$. So that, increasing the fin density as in (case 1) reduced the speed of the air passing between the fins, which reduced the cooling ratio of the manifold surface. While, halving the fin thickness as in (case 4) made only a small change in manifold cooling, as the same did in using short height fins in (case 2). Case 3 shows the best improvement in heat transfer where the surface temperature and exhaust gases were obtained the lowest results compared with other cases.

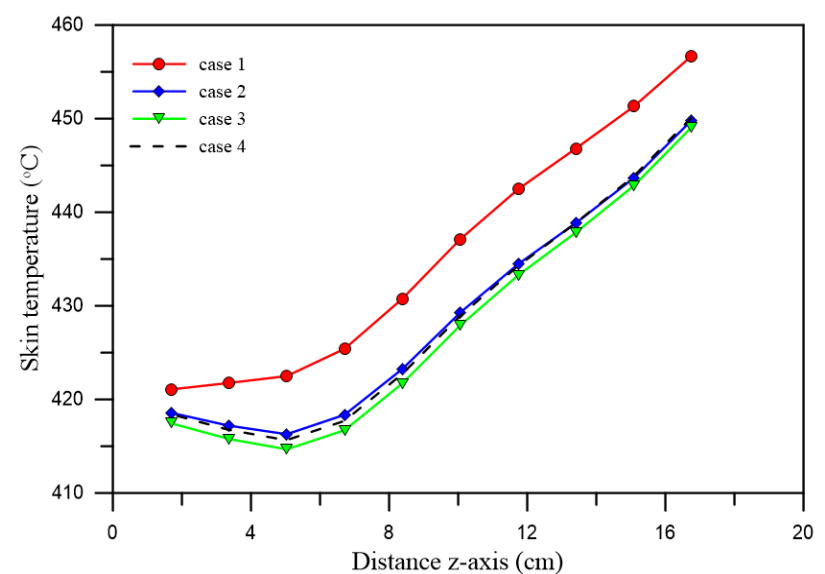

(a)

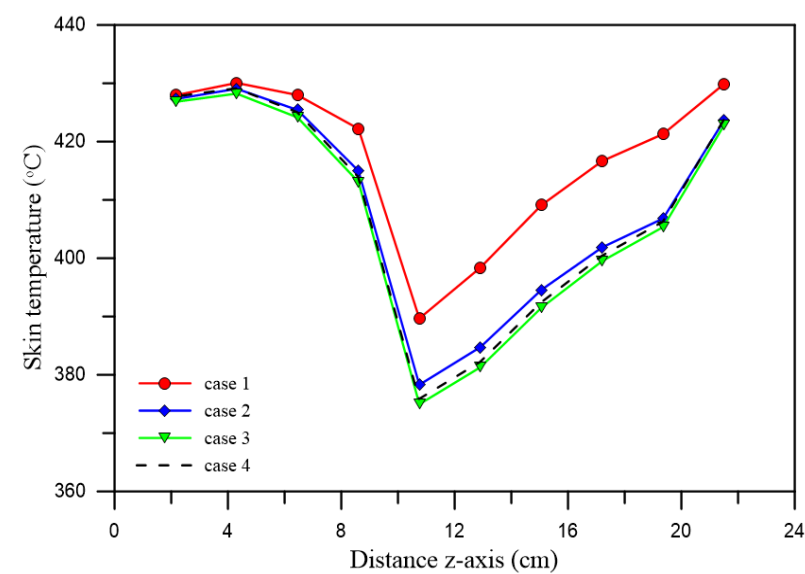

(b)

Fig. 11. Effect fin parameter on wall temperature: (a) upper pipe, (b) lower pipe

Figure 12 describes the velocity contour of the straight finned manifold for the best results in case 3 at operating condition of $3000 \mathrm{rpm}$. The numerical results of the finned exhaust manifold (case 3 ) with a range of engine speed 1000-3000 rpm were shown in Figure 13 and Figure 14 respectively. 
Table 6

Predicted fin cooling effects

\begin{tabular}{lllll}
\hline Manifold & Case & TC-9 & TC-10 & $\mathrm{T}_{\mathrm{g}}$ (outlet) \\
\hline Upper pipe & Without fins & 490 & 458 & 641 \\
& 1 & 449 & 423 & 634 \\
& 2 & 443 & 417 & 634 \\
& 3 & 441 & 415 & 634 \\
& 4 & 442 & 415 & 634 \\
\hline Manifold & Case & TC-11 & TC-12 & $\mathrm{T}_{\mathrm{g}}$ (outlet) \\
& Without fins & 435 & 482 & 617 \\
& 1 & 430 & 413 & 613 \\
& 2 & 429 & 397 & 613 \\
& 3 & 428 & 394 & 613 \\
& 4 & 428 & 395 & 613 \\
\hline
\end{tabular}

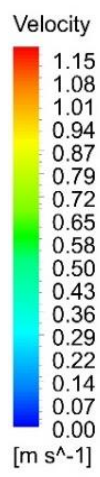

$\underset{2019 \text { R1 }}{\text { ANSYS }}$

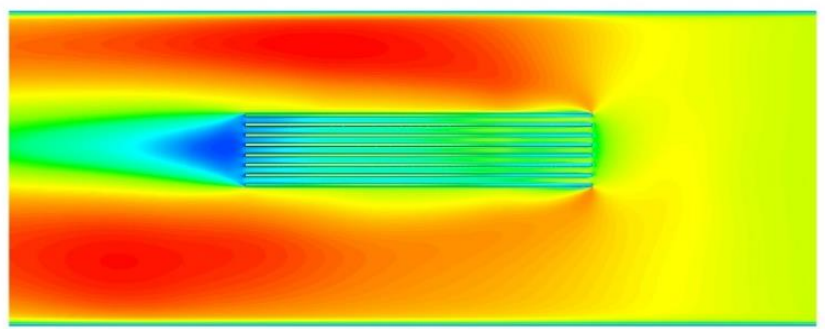

Fig. 12. Velocity contour of straight finned manifold (3000 rpm)

Skin Temperature

[C]

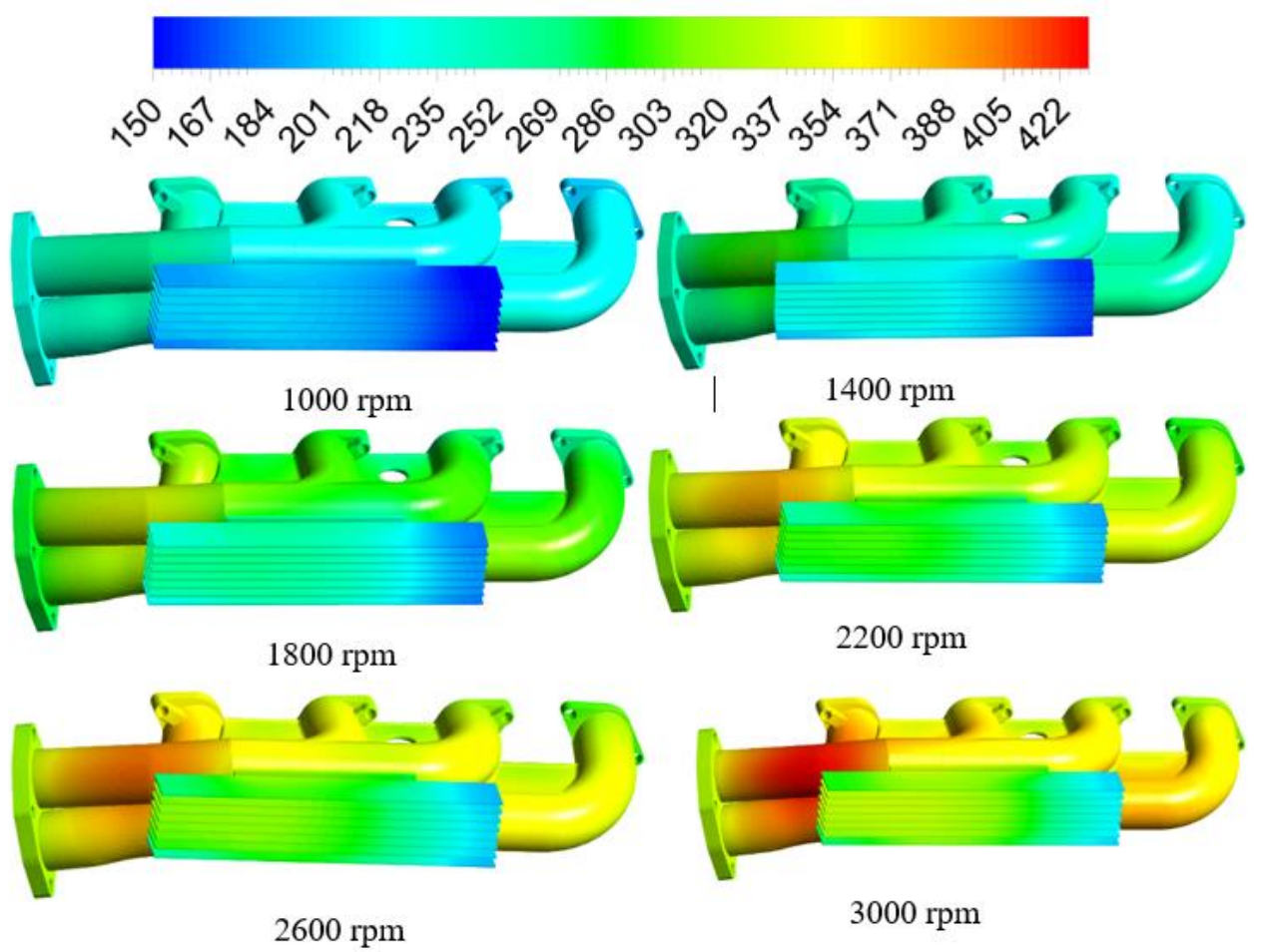

Fig. 13. Temperature contour of the straight finned exhaust manifold 


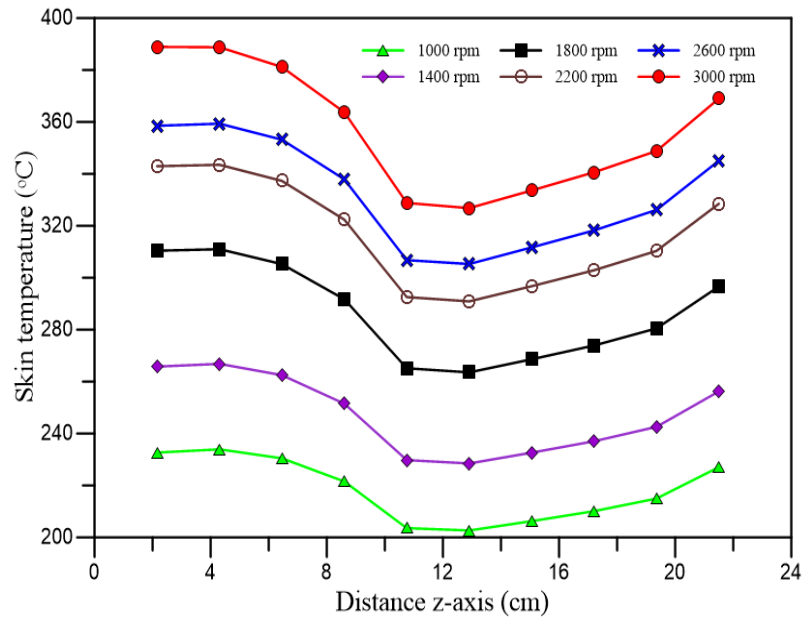

(a)

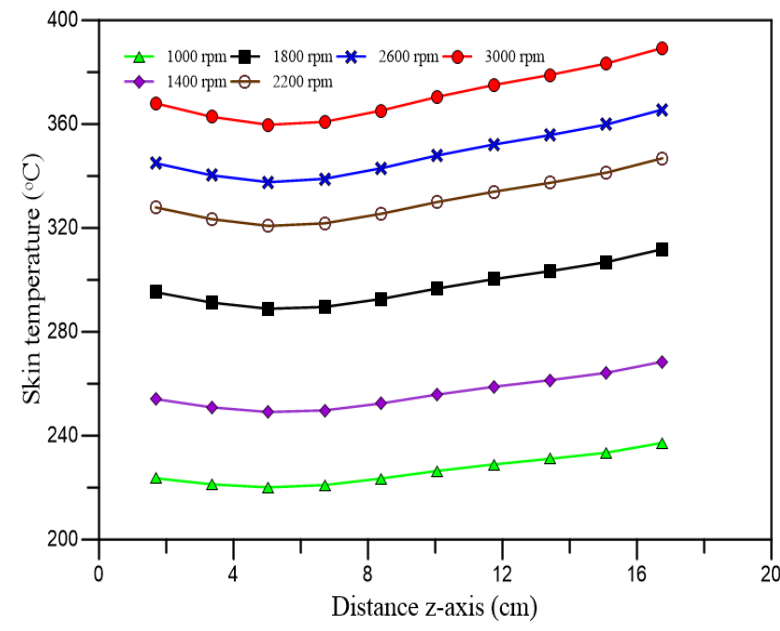

(b)

Fig. 14. Temperature distribution vs. distance: (a)upper pipe, (b) lower

\subsubsection{Sinusoidal fin geometrical model}

The aim of using sinusoidal fin was to create swirls in the flow of air passing through the fins which give good heat transfer improvements. The vortex as clearly is shown in Figure 18 are formed due to the fluctuations of the fins, which provide an additional mechanism for heat transfer in addition to the molecular diffusion. The numerical simulation was conducted for four models of sinusoidal fins; the geometrical as detailed in Table 1, also the geometrical shape as shown in Figure 3, to obtain the best performance with the minimum amount of material usage. The predicted mean manifold temperature at the same thermocouple locations in the experimental work and the manifold-out exhaust gas temperature were presented in Table 7, and the distributions of skin temperature along the length of the upper and lower pipe are presented in Figure 15. When $46-\mathrm{mm}$ fins spaced $10 \mathrm{~mm}$ as in (case 7) apart were installed on the exterior surface of the exhaust manifold. The lower pipe of the exhaust cooled about $117^{\circ} \mathrm{C}$ at TC-12. The exhaust cooling was dispersed only $5^{\circ} \mathrm{C}$. So, increasing the fin density as in (case 5) reduced the speed of the air passing through them, and therefore, reduced the cooling of the manifold surface. Halving the fin thickness as in (case 8 ) causes only a small change in the manifold cooling, same as did in using short height fins in (case 6). Figure 16 and Figure 17 explain the temperature contour and temperature distribution of the Sinusoidal finned exhaust manifold, especially in (case 7) with operating conditions at a range of engine speed 10003000 rpm respectively.

Table 7

Predicted fin cooling effect

\begin{tabular}{lllll}
\hline Manifold & Case & Tc-9 & TC-10 & $\mathrm{Tg}_{\mathrm{g}}$ (outlet) \\
\hline Upper pipe & plain & 490 & 458 & 641 \\
& 5 & 436 & 408 & 636 \\
& 6 & 427 & 401 & 636 \\
& 7 & 423 & 398 & 636 \\
& 8 & 423 & 399 & 636 \\
\hline Manifold & Case & TC11 & TC12 & $\mathrm{T}_{\mathrm{g}}$ (outlet) \\
& plain & 435 & 482 & 641 \\
& 5 & 425 & 386 & 636 \\
& 6 & 424 & 369 & 636 \\
& 7 & 422 & 365 & 636 \\
& 8 & 423 & 364 & 636 \\
\hline
\end{tabular}




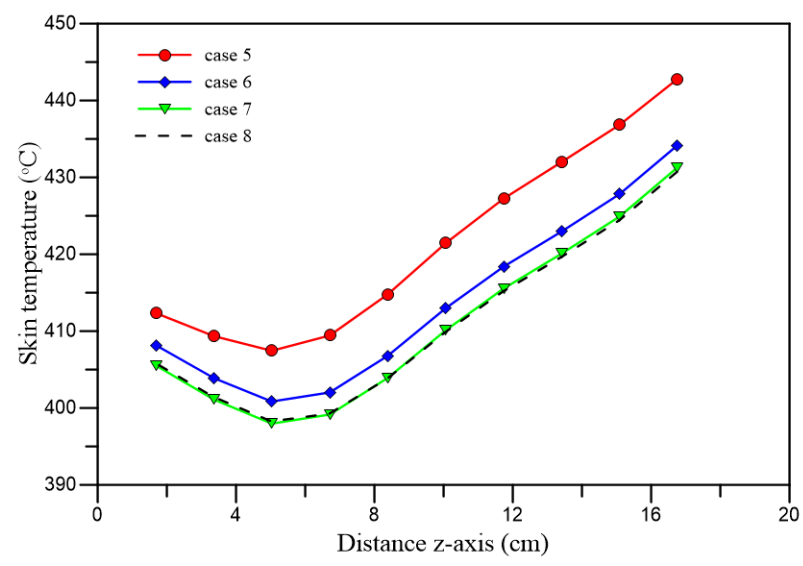

(a)

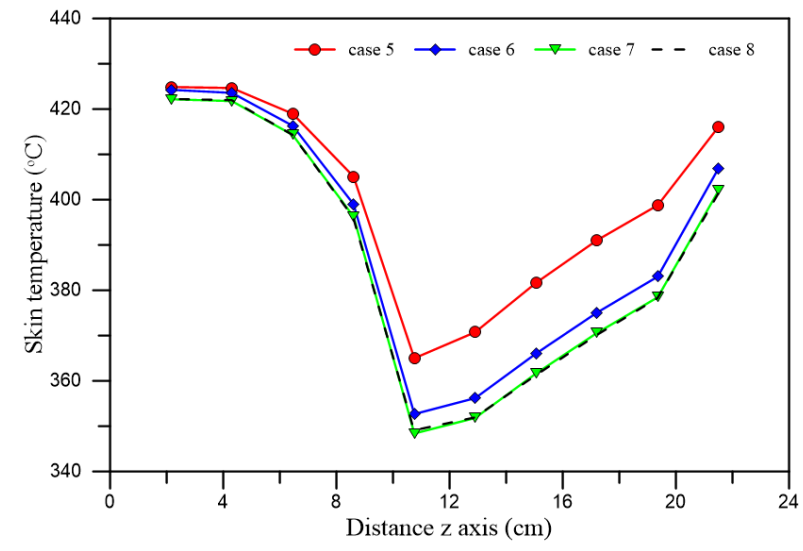

(b)

Fig. 15. Effect fin parameter on wall temperature: (a) upper pipe, (b) lower pipe

Skin Temperature

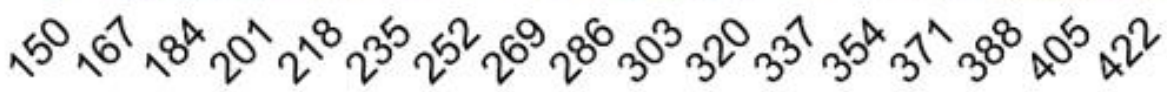

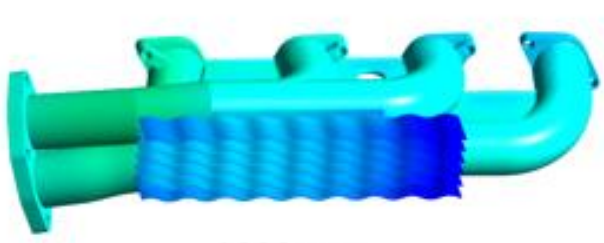

$1000 \mathrm{rpm}$

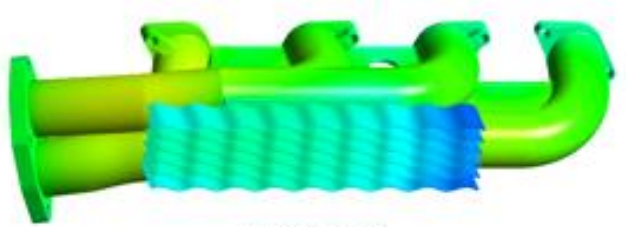

$1800 \mathrm{rpm}$

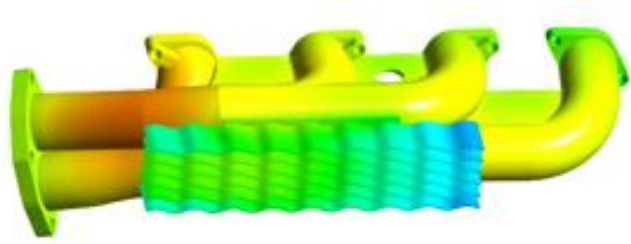

$2600 \mathrm{rpm}$
[C]

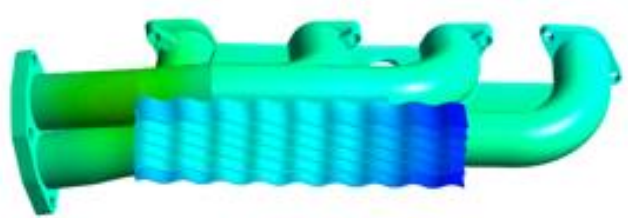

$1400 \mathrm{rpm}$

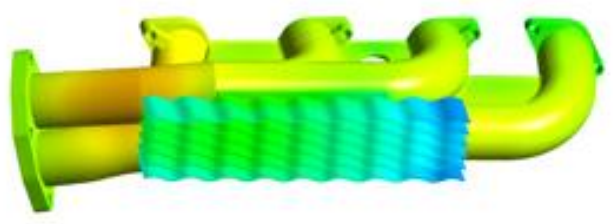

$2200 \mathrm{rpm}$

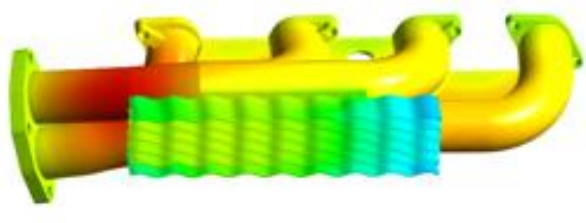

$3000 \mathrm{rpm}$

Fig. 16. Temperature contour of a sinusoidal finned exhaust manifold (case 7) 


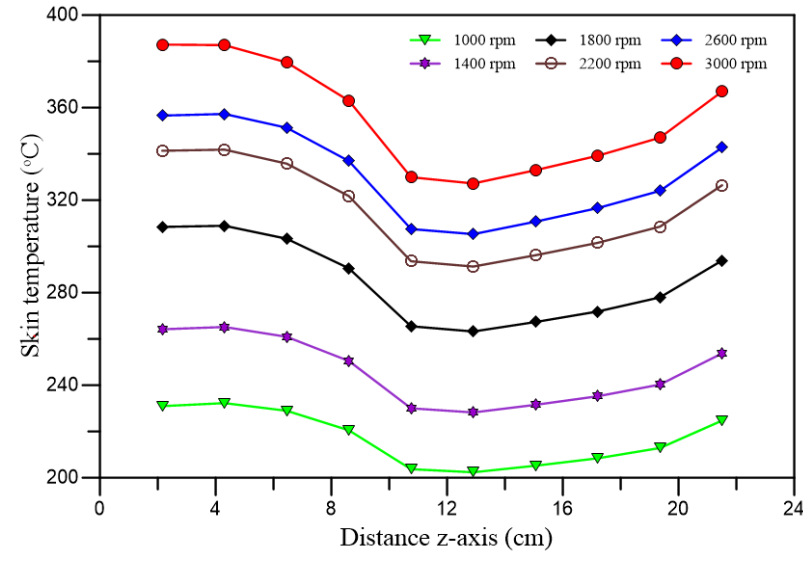

(a)

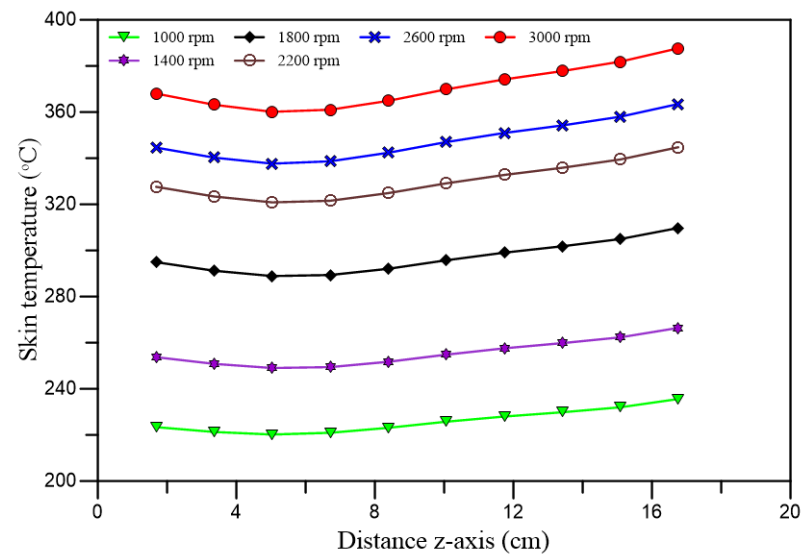

(b)

Fig. 17. Temperature distribution vs. distance: (a)upper pipe, (b) lower pipe

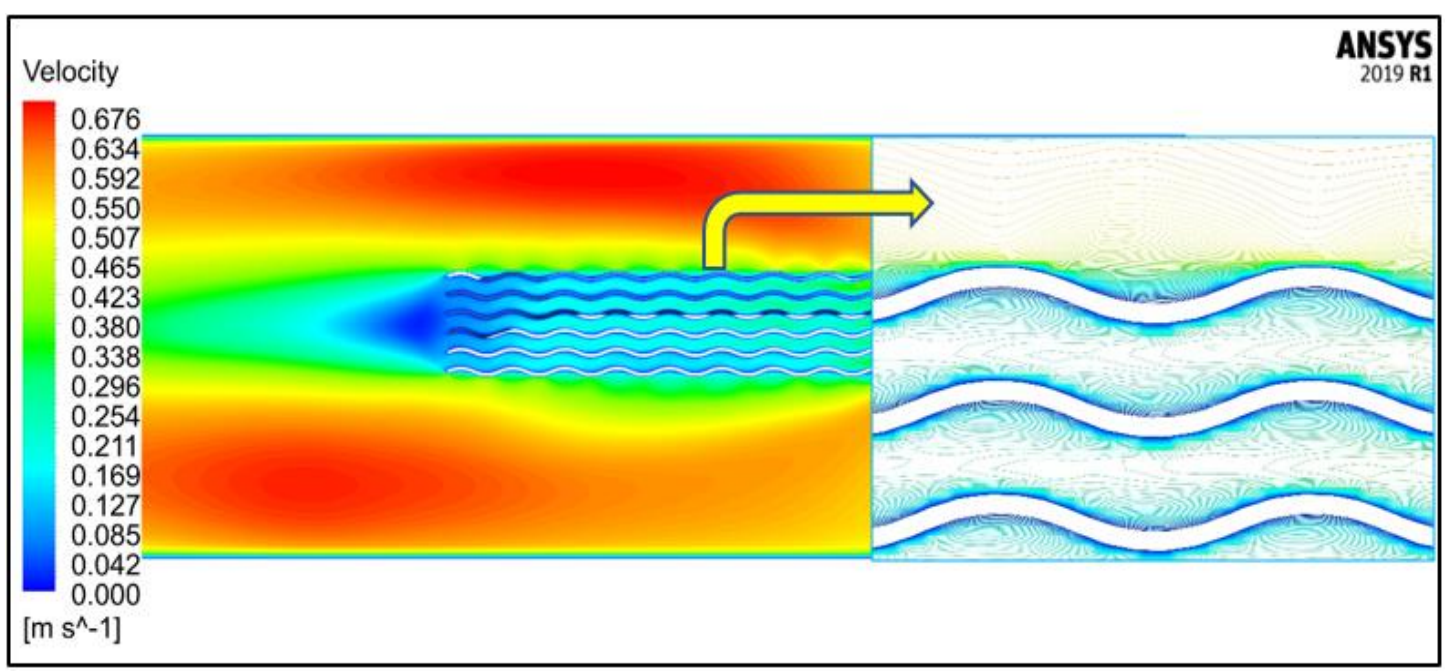

Fig. 18. Velocity contour of a sinusoidal finned manifold

\subsection{Experimental Results}

The steady-state testing matrix presented in Table 4 were to provide a range of operating conditions that encompassed the load range of the automotive engine. All the tests run using the chassis dynamometer set in speed control mode to keep the engine speed constant. Data were recorded minimally at three minutes per test after each condition reached thermal equilibrium. The experimental modification was based on the geometrical models (cases) that produced the best numerical simulation results, which means selecting case 3 for the straight finned exhaust type and case 7 for the sinusoidal finned type to be manufactured and then tested experimentally. Figure 19 shows the comparison of the measured skin temperature for the without fin (plain) exhaust manifold with the two types of finned exhaust at the locations TC-9 and TC- 12 . The difference in skin temperatures increases as the engine speed increases until it reaches $89^{\circ} \mathrm{C}$ at TC-9, while, reaching $132{ }^{\circ} \mathrm{C}$ at TC-12 when maximum speed reached to (2200 rpm). 


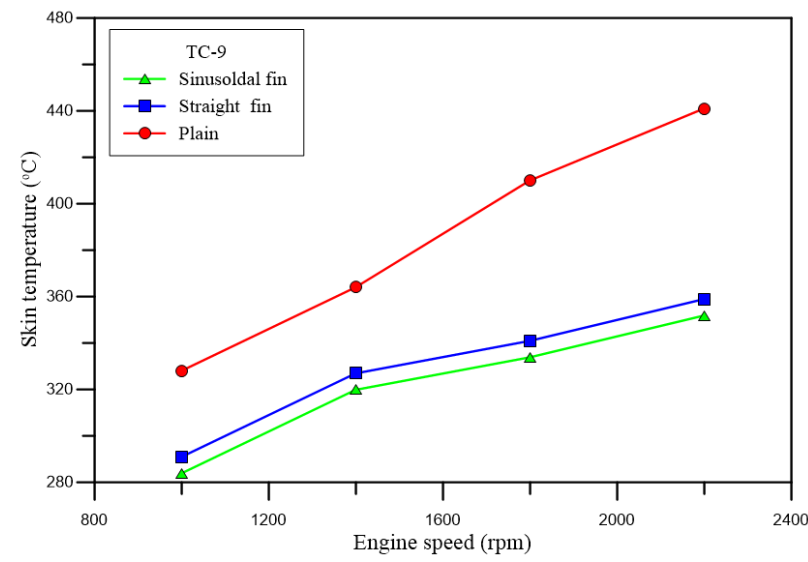

(a)

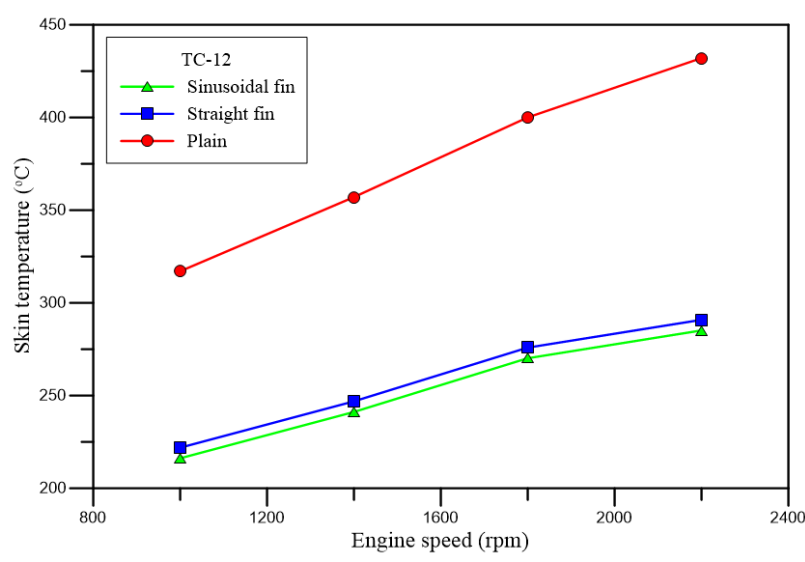

(b)

Fig. 19. The comparison of skin temperature measured vs. engine speed at:(a) TC-9, (b) TC-12

According to the experimentally recorded data, the sinusoidal finned exhaust has the highest improvements. Therefore, to compare the best experimental improvement data with the numerical simulation results at different ranges of engine operating conditions. The selected engine speeds for the verification were (1000-2200 rpm) during the four cases of the sinusoidal finned type at a constant load of $24 \mathrm{~N} . \mathrm{m}$ as shown in Figure 20. The comparison shows that the highest deviation ratio was at location TC-11 which is approximately $11 \%$, while the lowest deviation was at location TC-12 about $1.8 \%$. The same procedure applied to the straight fin model showed the rate of deviation ratio was about $12 \%$.
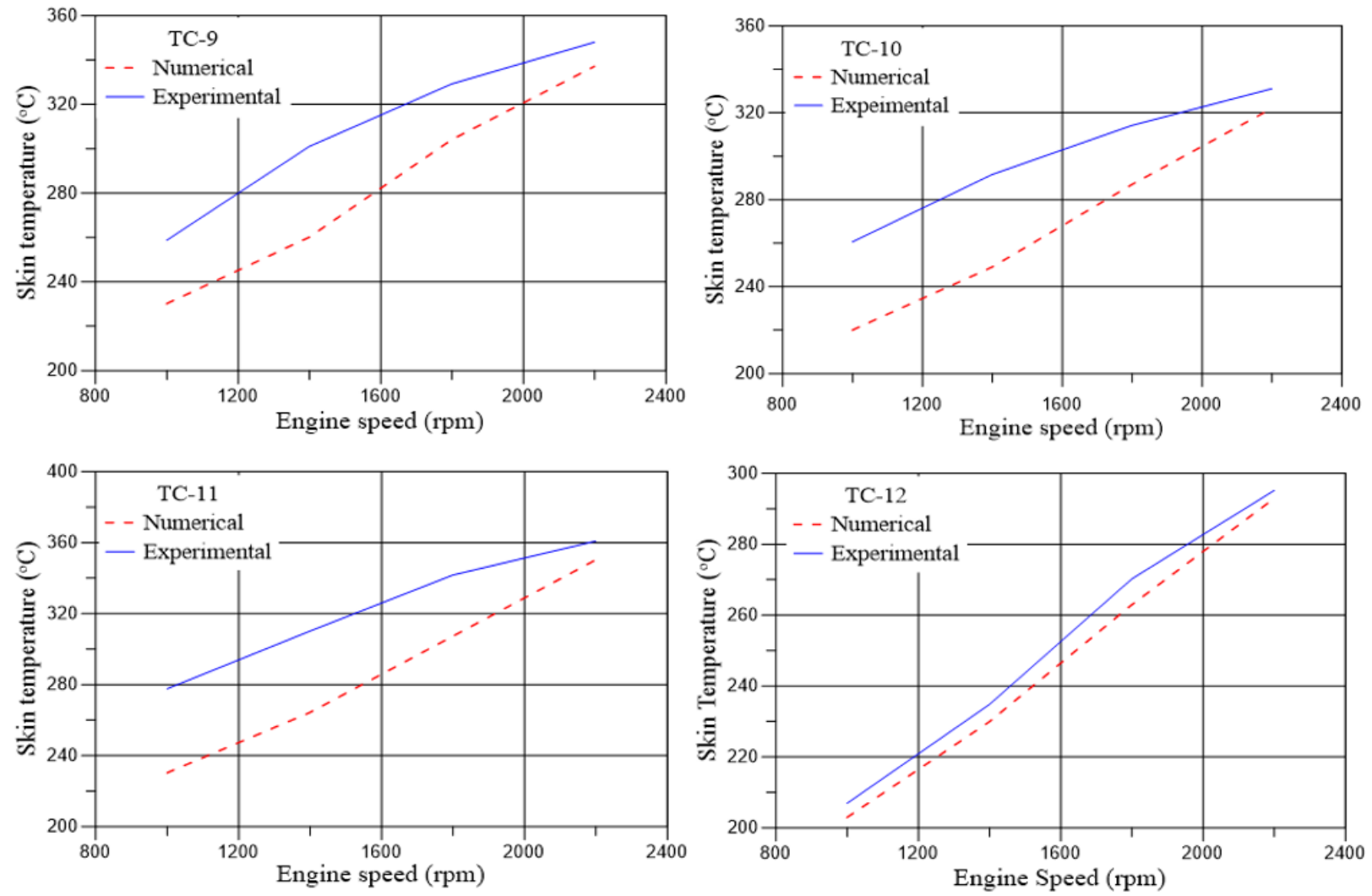

Fig. 20. Numerical and measured wall temperatures vs. engine speed with constant load at various thermocouple locations for Sinusoidal finned manifold 


\subsection{Data Analysis}

The analysis of the comparison between the numerical and experimental results show the effect of adding fins on the exhaust manifold thermal improvements. The installation of fins on the outer surface of the exhaust manifold has a less effect on the temperature of the exhaust gases, it is decreased by $7{ }^{\circ} \mathrm{C}$ only as cleared in Figure 21 . Figure 22 shows the comparison between the numerical results of temperature distribution on plain and finned exhaust manifold at engine speed $2200 \mathrm{rpm}$ and $24 \mathrm{~N} . \mathrm{m}$ load. The effect of fin installation reduced the surface temperature along the exhaust manifold, especially the middle section where the temperature drops to more than $100^{\circ} \mathrm{C}$. The sinusoidal fin model achieved slightly better results than the straight model despite the small surface area, where it was $\left(0.189 \mathrm{~m}^{2}\right)$ compared to $\left(0.215 \mathrm{~m}^{2}\right)$ for the straight model. Figure 23 shows a comparison of surface temperature at a specific position of thermocouples (TC-9, TC-12) within a range of engine speeds operating from (1000-3000) at a constant load of $24 \mathrm{~N}$.m. The heat extraction from the finned exhaust manifold peaked at TC-12, which is located in the middle of the lower pipe approximately in the section below the fin base, where the temperature difference reached $117{ }^{\circ} \mathrm{C}$ at $3000 \mathrm{rpm}$. This thermal improvement based on extracting heat from the exhaust by using fins and thus, its effect on the thermal loading on the exhaust manifold, which is positively reflected in saving the exhaust manifold from thermal loading failure.

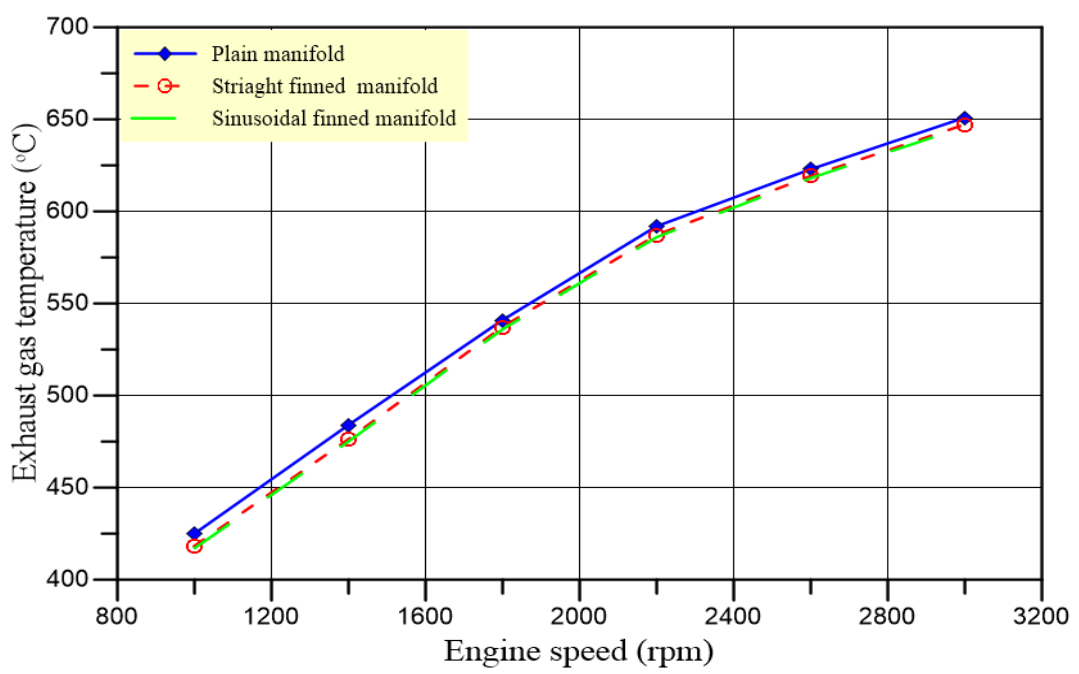

Fig. 21. Compare outlet gas temperature of the finned and plain manifold

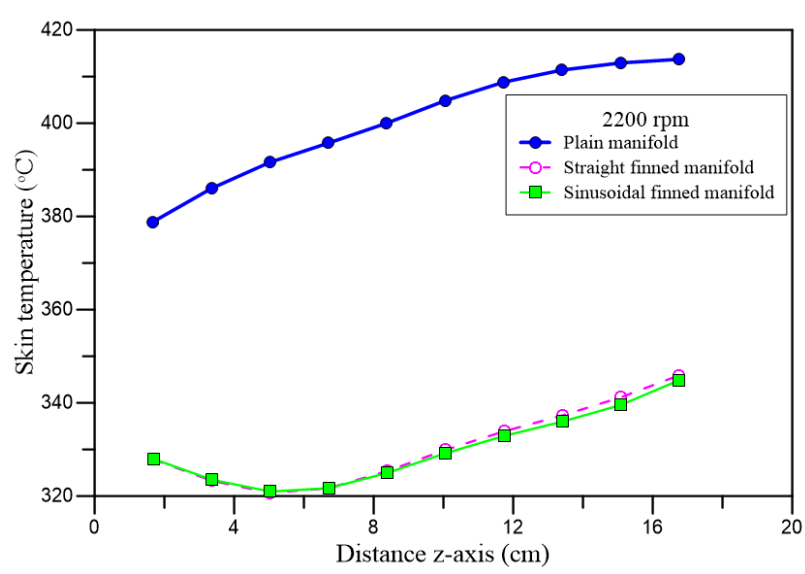

(a)

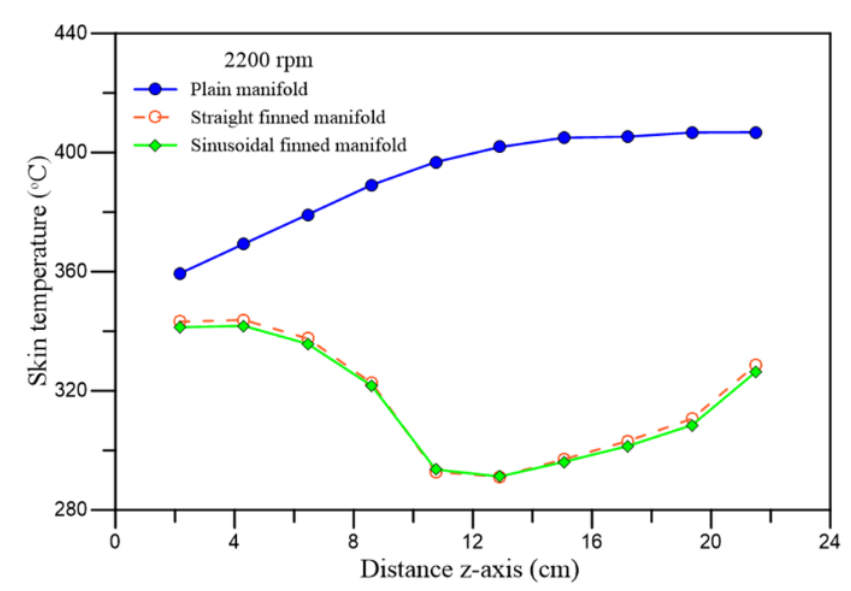

(b)

Fig. 22. Temperature distribution vs. distance of three-manifold models (a) upper pipe, (b) lower pipe 


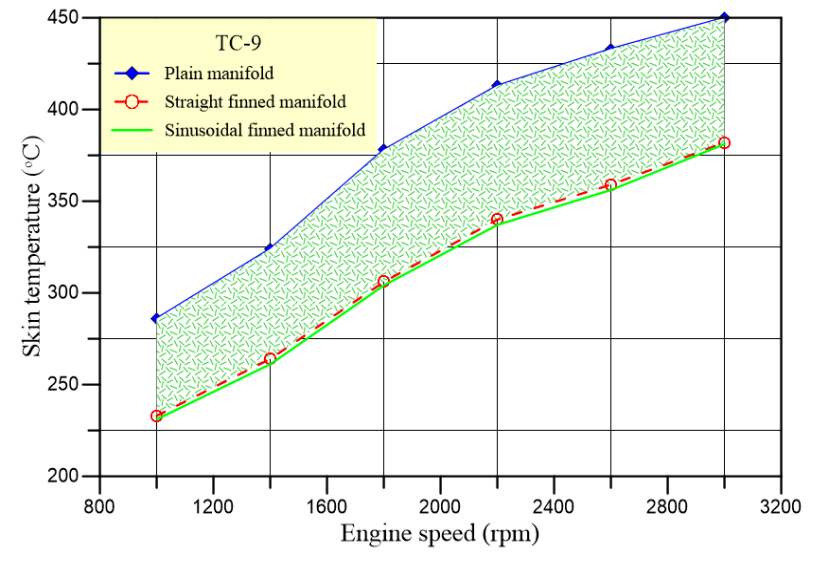

(a)

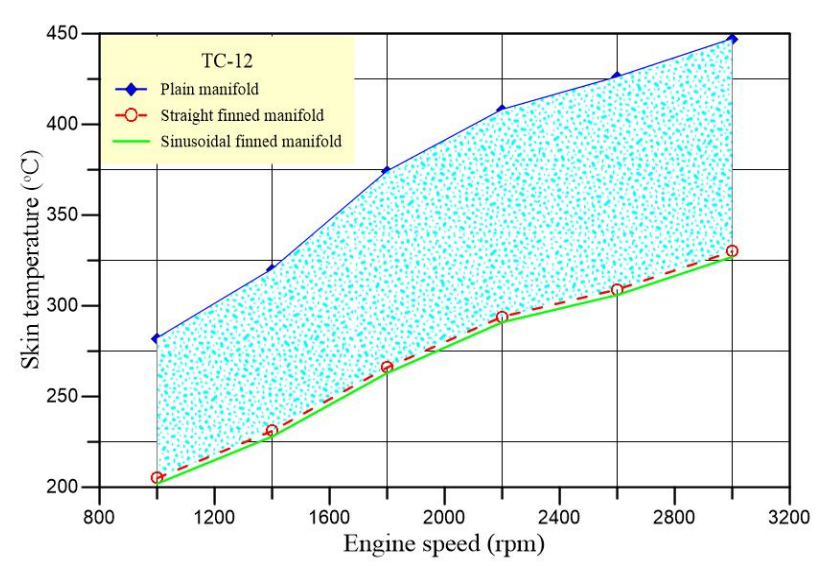

(b)

Fig. 23. Skin Temperature vs. Engine Speed:(a) TC-9, (b) TC-12

\section{Conclusions}

This present work focuses on analyzing the thermal loading distribution of the manifold exhaust experimentally and numerically. This analysis gives a chance to investigate the possibility to enhance its performance due to the manifold geometrical improvements. So, this research concluded that the numerical and experimental analysis of employing two fins types (straight and sinusoidal) with several effective parameters as spacing, height, and thickness found out the best performance achievement. The results of adding fins on the exterior surface of the exhaust manifold showed a good reduction for both surface temperature and exhaust gases. The sinusoidal fins model outperforms better than the straight fin model with a small margin of about $5{ }^{\circ} \mathrm{C}$. Finally, the temperatures of metal surface computed at thermocouple locations show good agreement to those recorded from the experimental test with a deviation of $11 \%$ and $1.8 \%$ for TC-11 and TC-12 of respectively. This description means that the modification of the geometrical shape of the manifold exhaust can give a good achievement to the thermal loading and hence, the structural thermal failure protection.

\section{Acknowledgment}

The authors would like to thank the staff of the combustion laboratory in the Department of Mechanical Engineering at the University of Technology for their serious cooperation for the success of this study.

\section{References}

[1] Pawłowski, B. "Critical points of hypoeutectoid steel-prediction of the pearlite dissolution finish temperature Ac1f." Journal of Achievements in Materials and Manufacturing Engineering 49, no. 2 (2011): 331-337. https://doi.org/10.4271/2010-01-0356

[2] Taylor, James, Neil Fraser, and Peter Wieske. "Water cooled exhaust manifold and full load EGR technology applied to a downsized direct injection spark ignition engine." SAE International Journal of Engines 3, no. 1 (2010): $225-240$.

[3] Cartwright, Justin, Ahmet Selamet, Robert Wade, Keith Miazgowicz, and Clayton Sloss. Heat Rejection and Skin Temperatures of an Externally Cooled Exhaust Manifold. No. 2015-01-1736. SAE Technical Paper, 2015. https://doi.org/10.4271/2015-01-1736

[4] Jha, Prabhat Kumar, K. Karunamurthy, Joy Das, and Rahul Malik. "Study of exhaust gas temperature of SI engine using water injection." Indian Journal of Science and Technology 9 (2016): 35. https://doi.org/10.17485/ijst/2016/v9i35/92817

[5] Milanovic, Rade, Chenn Q. Zhou, Jim Majdak, and Robert Cantwell. "CFD modeling of flow and heat transfer inside a liquid-cooled exhaust manifold." In ASME 2003 Heat Transfer Summer Conference, pp. 785-792. American Society of Mechanical Engineers Digital Collection, 2003. 
https://doi.org/10.1115/HT2003-47294

[6] Saravanan, J., T. N. Valarmathi, Rajdeep Nathc, and Prasanth Kumar. "Experimental Analysis of Exhaust Manifold with Ceramic Coating for Reduction of Heat Dissipation." In IOP Conference Series: Materials Science and Engineering, vol. 197, no. 1, p. 012051. IOP Publishing, 2017. https://doi.org/10.1088/1757-899X/197/1/012051

[7] Hoseini, Seyed Salar, Gholamhassan Najafi, and Barat Ghobadian. "Thermal and fluid simulation of a new diesel engine cooling exhaust gas recirculation system to reduce exhaust gas emissions." Journal of Advanced Research in Fluid Mechanics and Thermal Sciences 51, no. 2 (2018): 197-208.

[8] Al Doori, Wadhah Hussein Abdulrazzaq, "Effect Of Using Various Longitudinal Fin Number In Finned Channel Heat Exchangers On Heat Flow Characteristics." Journal of Advanced Research in Fluid Mechanics and Thermal Sciences 53, no. 1 (2019): 1-10.

[9] Durat, Mesut, Zekeriya Parlak, Murat Kapsiz, Adnan Parlak, and Ferit Fiçici. "CFD And Experimental Analysis On Thermal Performance Of Exhaust System Of A Spark Ignition Engine." Isi Bilimi ve Teknigi Dergisi/Journal of Thermal Science \& Technology 33, no. 2 (2013).

[10] Touloukian, Y. S., and T. Makita. Thermophysical properties of matter-the TPRC data series. Volume 6. Specific heatnonmetallic liquids and gases. (Reannouncement). Data book. No. AD-A-951940/6/XAB. Purdue Univ., Lafayette, IN (United States). Thermophysical and Electronic Properties Information Center, 1970.

[11] Ansys, I. "ANSYS meshing user's guide." vol 15317 (2010): 724-746.

[12] Jiji, Latif M., and Latif Menashi Jiji. Heat convection. Berlin: Springer, 2006.

[13] Cengel, Yunus A., S. Klein, and W. Beckman. Heat Transfer: A Practical Approach, vol. 141. New York, McGraw-Hill, 1998.

[14] Meng, J. A. "Enhanced heat transfer technology of longitudinal vortices based on field-coordination principle and its application." Power Engineering and Engineering Thermophysics, Tsinghua University, Beijing (2003). 